\title{
Relationship between allergic manifestations and Toxocara seropositivity: a cross-sectional study among elementary school children
}

\author{
J. Buijs*, G. Borsboom**, M. Renting+, W.J.A. Hilgersom+r, \\ J.C. van Wieringen $\#$, G. Jansen $\#$, J. Neijens"
}

Relationship between allergic manifestations and Toxocara seropositivity: a cross-sectional study among elementary school children. J. Buijs, G. Borsboom, M. Renting, W.J.A. Hilgersom, J.C. van Wieringen, G. Jansen, J. Neijens. (CERS Journals Ltd 1997. ABSTRACT: Toxocara (the cause of visceral larva migrans in humans) and allergy have in common both elevated immunoglobulin $\mathrm{E}$ (IgE) levels and eosinophilia. In the present study, we investigated: 1) associations between Toxocara seropositivity and allergic manifestations; 2) risk factors for Toxocara infection; and 3) differences in Toxocara seroprevalence, allergic manifestations and the associations between these two, in children from urban and rural environments.

Blood samples from 1,379 Dutch urban and rural elementary schoolchildren, were examined for Toxocara antibodies, eosinophil numbers, total IgE concentrations, and the occurrence of inhaled allergen-specific IgE. Questionnaires investigating respiratory health and putative risk factors for infection were completed.

It was found that $8 \%$ of the children had Toxocara antibodies, occurring significantly less often in females than in males. The means of total serum IgE levels and blood eosinophils were significantly higher in the Toxocara-seropositive than in the seronegative group. Allergic asthma/recurrent bronchitis was found in $7 \%$ of the children, allergic reaction on animal contact in $4 \%$, and IgE to at least one inhaled allergen in $16 \%$. These variables were associated with Toxocara seroprevalence. Inhaled allergen-specific IgE and asthma/recurrent bronchitis occurred significantly less often in rural than in urban areas, and significantly less often among girls than among boys. Furthermore, occurrence of allergen-specific $\mathbf{I g E}$ increased significantly with age. No association existed between Toxocara seroprevalence and assumed risks, i.e. contact with pet animals and public playgrounds.

In conclusion, our results indicate that allergic manifestations occur more often in Toxocara-seropositive children. A relationship with an already existing allergic condition is plausible.

Eur Respir J 1997; 10: 1467-1475.
*Laboratory for Parasitology and Mycology, National Institute of Public Health and Environment, Bilthoven, The Netherlands. **Physiology Dept and +Faculty of Medicine, Leiden University, Leiden, The Netherlands.

Public Health Services, Depts of Youth Health Care of ${ }^{++}$Nieuwegein, $\ddagger$ Utrecht and $\$$ Eindhoven, The Netherlands. \#Sophia Children's Hospital, Dept of Pediatrics, Subdepartment of Infectious and Immune Diseases, Erasmus University, Rotterdam, The Netherlands.

Correspondence: J. Buijs

Laboratory for Parasitology and Mycology National Institute of Public Health and Environmental Protection

PO Box 1

3720 BA Bilthoven

The Netherlands

Keywords: Allergic manifestations, immunoglobulin $\mathrm{E}$, inhaled allergen-specific, immunoglobulin E, Toxocara seroprevalence

Received: May 391996

Accepted after revision March 11997
Recent investigations suggest an increasing prevalence of childhood asthma $[1,2]$. Children at risk are those with an atopic constitution [3, 4]. The age at which allergy becomes manifest depends mainly on the degree of exposure to inhaled allergens, the most obvious being that to house dust mite (Dermatophagoides pteronyssinus) allergen [5]. Frequent exposure to allergens may accelerate expression of allergic symptoms at a young age [6]. Various products of biological origin, such as antigens derived from parasitic worms, have polyclonal $\mathrm{B}_{\varepsilon}$-cell-activating properties, and can, thereby, induce high serum total immunoglobulin E ( $\operatorname{IgE})$ concentrations $[7,8]$.

Toxocara spp., intestinal parasites of dogs and cats, may spend part of their life cycle in noncompatible hosts, including humans. Toxocara is endemic in the Netherlands. About $8 \%$ of the children have antibodies to this roundworm [9]. Eggs are passed on the soil with $\mathrm{dog} / \mathrm{cat}$ faeces; the infection, therefore, is soil transmitted. Larvae, hatched in the intestine from ingested eggs, migrate to the body tissues, such as liver and lungs. In noncompatible hosts, the larvae do not develop, and may survive as such for over 2 yrs [10]. Hatched larvae release excretory/secretory antigens [11] during migration, that provoke immuno-inflammatory reactions [8]. This results in a variety of ailments, including those of the respiratory tract [7].

In a longitudinal study of experimentally infected $\mathrm{BALB} / \mathrm{c}$ mice, we observed that a raised serum total IgE concentration and mixed cellular pulmonary inflammation lasted for more than 3 months [8]. The initially eosinophilic inflammation had obtained chronic appearance at 3 months postinfection. On investigating lung function in the mouse model, we found that pulmonary resistance was significantly increased and lung dynamic compliance decreased [12]. Studies by other investigators, performed in humans and animals, demonstrated that a major part of the newly produced IgE was nonparasite-specific [13-15], showing the polyclonal character of $B_{\varepsilon}$-cell stimulation. 
In a previous epidemiological study, we demonstrated elevated serum total $\operatorname{IgE}$ levels and a more frequent occurrence of inhaled allergen-specific IgE in Toxocaraseropositive as compared to seronegative children. The sample comprised 4-6 yr old elementary schoolchildren from two densely populated Dutch urban areas. This study also suggested an association of Toxocara seroprevalence with physician-confirmed asthma [9]. It was assumed that seropositive children had, or had experienced, an infection with Toxocara.

The endemicity of Toxocara in the Netherlands $[9$, 16], together with the pathological phenomena described above, suggest that infection with this kind of parasitic roundworm may accelerate expression of asthma-like affections in susceptible children, and possibly aggravates already-existing asthma. Such an association may be important in view of the increasing number of children having such affections.

In the present cross-sectional study, we investigated whether an association between toxocarosis and allergic manifestations could be established in elementary schoolchildren, aged 4-12 yrs, of urban or rural origin. We also investigated whether risk factors for infection with Toxocara could be identified in this age group. The study enabled us to establish whether differences existed between urban and rural areas in the prevalence of Toxocara antibodies and allergic manifestations, and in the relationship between these two conditions. Furthermore, the similar design of the previous and present study allowed comparison of results. The presence of allergic manifestations was to be estimated from questionnaires, from eosinophil numbers, total serum $\operatorname{IgE}$ concentration, and from the presence of inhaled allergen-specific IgE.

\section{Materials and methods}

\section{Population}

The investigation was carried out among 1,379, 4-12 yr old, elementary schoolchildren from urban and rural areas in the provinces of Utrecht and Brabant in the Netherlands. Six hundred and eighty three of the children lived in the province of Utrecht: 335 in Utrecht city (urban), distributed over three schools; and 348 in the countryside (rural), distributed over seven schools. Six hundred and ninety six of the children lived in the province of Brabant: 328 in Eindhoven city (urban), distributed over three schools, and 368 in the countryside (rural), distributed over two schools. The province of Utrecht is located in the centre and that of Brabant in the south of the Netherlands. Both provinces have similar demographic characteristics. Schools were selected in co-operation with the community health services, in order to obtain representative samples of the population.

The surveys were carried out in Utrecht from November 1989 to April 1990, and in Brabant from December 1991 to February 1992. To control for socioeconomic status in the samples from the city populations, schools were selected on the basis of the socioeconomic category (low, middle and high) of the neighbourhoods. National criteria, such as the parents' education, income and housing, were used to categorize the schools; this information was provided by the Municipal Centers for Research and Statistics. An estimated $85 \%$ of the pupils attending a particular school were of the same socioeconomic category as the neighbourhood in general. Division by socioeconomic categories was not meaningful in the countryside. In rural Utrecht, each village had its own small size school attended by all children in the vicinity. In rural Brabant, larger schools served larger areas.

The parents were asked to complete a questionnaire, which, together with a letter of consent for the participation of their child(ren), was returned to the school staff. Per school, $60-85 \%$ of the parents returned the letter of consent. Ethical aspects were considered and approved by an independent group of public health authorities of the Public Health Services. No such investigation has been performed in any of the study areas previously.

\section{Blood collection and examination}

Schools were visited from 09.00 until $12.00 \mathrm{~h}$, and 30-80 samples were collected per visit. For reasons of anonymity, serial numbers were given to questionnaires and blood samples. A $0.5 \mathrm{~mL}$ sample of blood was collected by finger prick and was transferred into a $2 \mathrm{~mL}$ anti-coagulant (dipotassium ethylenediamine tetra-acetic acid) containing tube. The blood was centrifuged at 2,500 $\mathrm{rpm}$ for $15 \mathrm{~min}$. The plasma collected was divided between two tubes, one for Toxocara serology and the other for measurements of total and inhaled allergenspecific IgE. The tubes were stored at $-20^{\circ} \mathrm{C}$ until used.

\section{Toxocara serology}

Antibodies to Toxocara were measured, as described by VAN KNAPEN et al. [17]. Peroxidase-labelled rabbitanti-human immunoglobulin G (IgG) (Institut Pasteur, Marnes la Coquette, France) was used as a conjugate. Each microtitre plate contained 7-9 control sera, i.e. 6-8 known negative samples and one standard serum with known Toxocara antibody titre. Since contact of the children with Toxocara (and not disease) was subject to study, the sera were screened in a 1:20 dilution, the lowest dilution at which specific antibodies were detected. Results were considered positive when the extinction value was higher than the mean extinction value of 6-8 negative control sera raised with three times the standard deviation. Results were expressed as either negative or positive. Antibody measurement was performed according to good laboratory practice procedures, including the required controls for approval of new batches of reagents.

Estimations of serum total IgE concentration and of IgE specific for inhaled allergens

The PharmaciaCAP System IgE radioimmunoassay (RIA) and the PharmaciaCAP System radioallergosorbent test (RAST) were used for the estimation of serum 
total $\operatorname{IgE}$ and of inhaled allergen-specific $\operatorname{IgE}$, respectively. The CAP System included equipment, test kits and all required control and standard sera. The tests are based on the ImmunoCAP technology. Briefly, the antigens, anti-IgE or allergens, are covalently coupled to cyanogen bromide-activated sepharose beads (ImmunoCAP). IgE or inhaled allergen-specific IgE, when present in the serum, reacts with the ImmunoCAP. Radioactively labelled antibodies against IgE are then added, which bind to the complex. The radioactivity of the complex formed is measured in a gamma counter. The amount of bound radioactivity is a measure of the quantity of total IgE or inhaled allergen-specific IgE. The detection limit for total $\mathrm{IgE}$ is $0.8 \mathrm{kU} \cdot \mathrm{L}^{-1}$ and for inhaled allergen-specific $\operatorname{IgE}$ is $<0.35 \mathrm{kU} \cdot \mathrm{L}^{-1}$.

The allergens tested were Dermatophagoides pteronyssinus, Canis familiaris and Felis domesticus. Because, the majority of the sera containing IgE specific for $F$. domesticus and/or C. familiaris also contained D. pteronyssinus-specific IgE, the samples were categorized as either nonreacting or reacting with at least one allergen. Results are expressed as $\mathrm{kU} \mathrm{IgE} \cdot \mathrm{L}^{-1}$ for serum total $\mathrm{IgE}$, and as either negative or positive for inhaled allergen-specific IgE. A concentration of $>0.35 \mathrm{kU}$ of inhaled allergen-specific $\mathrm{IgE} \cdot \mathrm{L}^{-1}$ was considered positive.

\section{Estimations of Toxocara-specific IgE}

Toxocara-specific IgE was estimated by J-F. Magnaval (Toulouse, France), in six Toxocara-seropositive and seronegative samples, according to the method described by Magnaval et al. [18]. The Toxocara-positive sera were selected on the basis of varying total IgE concentrations. The Toxocara-negative samples (controls) were selected on the basis of high total IgE concentrations.

\section{Questionnaires}

Prior to visiting the school, the school staff, the parents and the general practitioners were informed in writing about the aim of the investigation, the life cycle of the parasite, and the route of infection. Questionnaires were distributed to the parents requesting: 1) name, date of birth, and sex of the child; 2) information concerning putative risk factors for infection, i.e. the presence of dogs and cats in the home, contact with animals outside the home, and use of public playgrounds; 3 ) information concerning allergic complaints, i.e. "Does the child suffer from asthma/recurrent bronchitis?", "Does the child react with allergic symptoms during or after contact with animals?", "Does the child suffer from eczema?"; and 4) whether the child had ever been hospitalized with asthma Questions about allergic symptoms were followed by: "If the answer is yes, has it been confirmed by a physician"? Asthma was diagnosed using national criteria, which are concordant with those of the American Thoracic Society. Recurrent bronchitis was mentioned, considering that 4 and $5 \mathrm{yr}$ olds are suspected of an asthmatic condition when they have recurrent bronchial ailments at that age. Answers were accepted only when allergic disorders observed by the parents were subsequently confirmed by a physician.

\section{Risk factors}

Putative risk factors were also investigated by questionnaire. The parents were asked: 1) whether or not the family owned dogs and/or cats, now or ever; 2) if their children played at public playgrounds; 3) and if the children had contact with animals which did not belong to the household.

\section{Statistical analysis}

Logistic regression analysis was used to study the associations between Toxocara seroprevalence and allergic manifestations, inhaled allergen-specific IgE, the risk factors, and the background variables: district (Utrecht versus Eindhoven), environment (urban vs rural), sex, school and age. These analyses were made using the EGRET package [19]. Firstly, the relationships between Toxocara seroprevalence and the five background variables were studied, and subsequently those between Toxocara seroprevalence and allergic manifestations, between Toxocara seroprevalence and inhaled allergenspecific IgE, and between Toxocara seroprevalence and the risk factors. The latter three associations were corrected for confounding effects of the background variables. School was entered in the models as a random effect, to account for the fact that children from the same school were more alike than children from different schools. Not adjusting for school in this way may cause an underestimation of confidence intervals of the odds ratios, which in its turn may lead to spuriously significant results [19]. For each model, all first order interactions between fixed effects were examined, and statistically significant ones were retained.

Analysis of covariance (ANCOVA) was used to study the relationships between Toxocara seroprevalence and serum immunoglobulin E concentration, and between Toxocara seroprevalence and eosinophil number. PROC GLM of the Statistical Analysis System (SAS) package [20] was used to perform these analyses. $\operatorname{IgE}$ and eosinophil values were log-transformed in order to achieve approximate normality. Toxocara seroprevalence and the background variables, district, environment and sex, were entered as fixed factors in the models. School was entered as a fixed blocking factor, nested under district and environment. Age was included as covariate. This design contained $2 \times 2 \times 15=60$ cells. One of the cells was empty in the $\operatorname{IgE}$ data and two cells were empty in the eosinophil data. To avoid the complication of analysing designs having some cells empty, one artificial observation was placed in each of these cells. These observations had the average IgE or eosinophil value for the particular combination of levels of the factors, Toxocara seroprevalence, district, environment and sex they were in, and also the average value for age. These observations were not included in the numbers of observations shown in the tables.

Initially, models containing all possible interactions of all orders between Toxocara seroprevalence, district, environment and sex were fitted. Interactions with school 
were assumed to be nonexistent. Nonsignificant interactions were sequentially removed, starting with those of highest order. When a significant interaction of order higher than one was found, all interactions of lower order included in that higher order interaction were also retained. Because the data were highly unbalanced, type III sums of squares [20] were used in hypothesis tests. These sums of squares do not depend on cell frequencies, and also allow interpretation of main effects in the presence of interactions. In the tables and in the text, we report least squares means transformed back to the original scale to describe average $\operatorname{IgE}$ and eosinophil levels in subgroups. Least squares means, also, do not depend on cell frequencies and, thus, on the degree of imbalance in the data.

All other results were calculated with the SAS package. In all analyses, p-values less than 0.05 were considered significant. In evaluating interaction terms, $p$-values less than 0.01 were used in view of the smaller statistical power of these tests.

\section{Results}

\section{Sample characteristics}

The number of children observed in each of the 15 schools, as well as the seroprevalence of Toxocara, asth$\mathrm{ma} /$ recurrent bronchitis and inhaled allergen-specific $\operatorname{IgE}$ are presented in table 1 . The numbers of subjects varied considerably among schools. Relatively small

Table 1. - Characteristics of the population studied on the basis of division into schools: Dutch elementary schoolchildren 1989-1992

\begin{tabular}{|c|c|c|c|c|c|}
\hline $\begin{array}{l}\text { School } \\
\text { No. }\end{array}$ & $\mathrm{n}$ & $\begin{array}{l}\text { Sex } \\
\mathrm{M} / \mathrm{F}\end{array}$ & $\begin{array}{c}\text { Toxocara } \\
+\mathrm{ve} \\
\%\end{array}$ & $\begin{array}{c}\text { Asthma/ } \\
\text { RB } \\
\%\end{array}$ & $\begin{array}{c}\text { Allergen- } \\
\text { specific } \\
\text { IgE } \\
\%\end{array}$ \\
\hline \multicolumn{6}{|c|}{ Utrecht: rural } \\
\hline 1 & 42 & $14 / 28$ & 10 & 2 & 14 \\
\hline 2 & 61 & $30 / 31$ & 10 & 7 & 12 \\
\hline 3 & 51 & $25 / 26$ & 4 & 2 & 8 \\
\hline 4 & 74 & $40 / 34$ & 5 & 3 & 11 \\
\hline 5 & 38 & $18 / 20$ & 24 & 18 & 5 \\
\hline 6 & 35 & $20 / 15$ & 6 & 9 & 17 \\
\hline 7 & 47 & $25 / 22$ & 2 & 2 & 13 \\
\hline \multicolumn{6}{|c|}{ Utrecht: urban } \\
\hline 8 & 101 & $48 / 53$ & 3 & 4 & 27 \\
\hline 9 & 79 & $40 / 39$ & 6 & 10 & 13 \\
\hline 10 & 155 & $72 / 83$ & 10 & 9 & 15 \\
\hline \multicolumn{6}{|c|}{ Eindhoven: rural } \\
\hline 11 & 185 & $93 / 92$ & 8 & 8 & 17 \\
\hline 12 & 183 & $96 / 87$ & 6 & 4 & 14 \\
\hline \multicolumn{6}{|c|}{ Eindhoven: urban } \\
\hline 13 & 117 & $63 / 54$ & 11 & 8 & 16 \\
\hline 14 & 118 & $55 / 63$ & 8 & 9 & 23 \\
\hline 15 & 93 & $49 / 44$ & 16 & 10 & 25 \\
\hline $\begin{array}{l}\text { Cohort } \\
\text { means }\end{array}$ & $1379 \llbracket$ & $(688 / 691)^{*}$ & 8 & 7 & 16 \\
\hline
\end{tabular}

n: number of children per school; M: male; F: female; +ve: positive; RB: recurrent bronchitis; IgE: immunoglobulin E. $\$$ : percentage of children having specific IgE against one or more inhalant allergens; $\uparrow$ : median age of the cohort was 8 yrs; *: Toxocara seroprevalence was $10 \%$ among males and $7 \%$ among females. numbers were observed in the seven schools in the rural vicinity of Utrecht. However, the numbers of children in each of the four regions were very similar, namely approximately 340 . Also, the number of boys and girls, 688 and 691 respectively, were almost equal.

We first studied whether living in the district of Utrecht or in the district of Eindhoven (district), living in an urban or in a rural environment (environment), sex, age or the school attended were associated with Toxocara seroprevalence. The overall seroprevalence of Toxocara was $8 \%$. We did not find a relationship with district (odds ratio (OR) 1.18; 95\% confidence interval $(95 \%$ CI) $0.66-2.11$ ) or with environment (OR 0.83 ; $95 \%$ CI 0.46-1.49). Significantly less girls (7\%) than boys $(10 \%)$ had Toxocara antibodies. Using boys as the baseline category, the OR for sex was 0.64 (95\% CI 0.44-0.95). However, this OR varied between the four subpopulations formed by combining the levels of district and environment in the sample studied. This was analysed by studying the association between Toxocara seropositivity and sex separately in each of the four strata. This revealed that the odds for Toxocara seropositivity were always smaller in girls than in boys, except in the city of Eindhoven, where girls had the larger odds. The OR for sex was significant in the city of Utrecht (OR 0.35; 95\% CI 0.13-0.93) and in rural Utrecht (OR 0.43; 95\% CI 0.18-1.05), but not in Eindhoven city (OR 1.49; 95\% CI 0.72-3.13) or in rural Eindhoven (OR $0.51 ; 95 \%$ CI $0.19-1.30)$.

Toxocara seroprevalence varied widely between the schools from a minimum of $2 \%$ to a maximum of $24 \%$ (table 1), which resulted in a highly significant random effect of school $(\mathrm{p}<0.001$, likelihood ratio test $)$ in the logistic regression model. The median age in the total sample was 8 yrs. Age did not show a relationship with Toxocara seroprevalence. Furthermore, no significant interactions were found between age and the other variables investigated.

\section{Association between Toxocara seroprevalence and allergic manifestations}

ORs for the associations between Toxocara seroprevalence and allergic manifestations, presented in table 2, were adjusted for the background variables, district, environment, sex and school. The allergic manifestations were not related to age. Age was, therefore, omitted from the models. Asthma/recurrent bronchitis and allergic reaction on animal contact were significantly associated with Toxocara seroprevalence, whereas eczema and hospitalization due to asthma/recurrent bronchitis were not. No statistically significant interactions between allergic manifestations and the background variables were found.

Association of inhalant allergen-specific IgE with Toxocara seroprevalence, district, environment, sex, school and age

Inhaled allergen-specific $\operatorname{IgE}$ was found significantly more often in the Toxocara-seropositive group as compared to the group in which no antibodies were 
Table 2. - Logistic regressions of allergic manifestations on Toxocara seroprevalence: Dutch elementary schoolchildren 1989-1992

\begin{tabular}{|c|c|c|c|c|c|c|}
\hline \multirow[t]{2}{*}{ Outcome } & \multirow[t]{2}{*}{ Toxocara } & \multicolumn{2}{|c|}{ Cases } & \multirow{2}{*}{$\begin{array}{c}\text { Crude }^{\dagger} \\
\text { OR }\end{array}$} & \multirow{2}{*}{$\begin{array}{c}\text { Adjusted } \\
\text { OR }\end{array}$} & \multirow[t]{2}{*}{$95 \% \mathrm{CI}^{\S}$} \\
\hline & & Total* & $(\%)$ & & & \\
\hline Asthma/RB & $\begin{array}{l}\text {-ve } \\
+\mathrm{ve}\end{array}$ & $\begin{array}{c}77 / 1257 \\
17 / 114\end{array}$ & $\begin{array}{r}(6) \\
(15)\end{array}$ & $\begin{array}{c}\text { Baseline } \\
2.69\end{array}$ & $\begin{array}{l}\text { Baseline } \\
2.49\end{array}$ & $1.41-4.39$ \\
\hline $\begin{array}{l}\text { Allergic reaction } \\
\text { on animal contact }\end{array}$ & $\begin{array}{l}\text {-ve } \\
+\mathrm{ve}\end{array}$ & $\begin{array}{c}41 / 1251 \\
12 / 113\end{array}$ & $\begin{array}{l}(3) \\
(11)\end{array}$ & $\begin{array}{c}\text { Baseline } \\
3.51\end{array}$ & $\begin{array}{l}\text { Baseline } \\
3.25\end{array}$ & $1.65-6.42$ \\
\hline Eczema & $\begin{array}{l}\text {-ve } \\
+\mathrm{ve}\end{array}$ & $\begin{array}{c}61 / 1252 \\
5 / 112\end{array}$ & $\begin{array}{l}(5) \\
(4)\end{array}$ & $\begin{array}{c}\text { Baseline } \\
1.18\end{array}$ & $\begin{array}{l}\text { Baseline } \\
0.86\end{array}$ & $0.34-2.19$ \\
\hline $\begin{array}{l}\text { Hospitalization } \\
\text { due to asthma/RB }\end{array}$ & $\begin{array}{l}-\mathrm{ve} \\
+\mathrm{ve}\end{array}$ & $\begin{array}{c}31 / 1258 \\
5 / 114\end{array}$ & $\begin{array}{l}(2) \\
(4)\end{array}$ & $\begin{array}{c}\text { Baseline } \\
1.82\end{array}$ & $\begin{array}{c}\text { Baseline } \\
1.58\end{array}$ & $0.59-4.22$ \\
\hline
\end{tabular}

*: number of cases of the outcome variable versus the total number of children in that Toxocara category; $\dagger$ : odds ratios (OR) versus baseline category; $\$$ : ORs adjusted for district, urban/rural environment, sex and school; \$: confidence intervals $(\mathrm{CI})$ of the adjusted OR. -ve: negative; +ve: positive; RB: recurrent bronchitis.

demonstrated (table 3). Furthermore, inhaled allergenspecific IgE was found significantly more often in children from urban than from rural backgrounds, and more often in boys than in girls. Also, its occurrence increased with age. No difference was observed between the districts of Utrecht and Eindhoven.

The considerable variation among schools in percentage of children presenting allergen-specific IgE, ranging $5-27 \%$ (table 1), turned out to be nonsignificant in this analysis after adjustment for the other variables in the model (table 3).

Association of eosinophil numbers and serum IgE levels with Toxocara seroprevalence

Overall, the number of eosinophils was higher in the Toxocara-seropositive group (221 cells $\mu \mathrm{L}^{-1}$; $95 \%$ CI $188-259$ cells $\left.\cdot \mu \mathrm{L}^{-1}\right)$ as compared to the seronegative group (175 cells $\cdot \mu \mathrm{L}^{-1} ; 95 \%$ CI $167-184$ cells $\left.\cdot \mu \mathrm{L}^{-1}\right)$, as indicated by a statistically significant main effect of Toxocara seroprevalence $(\mathrm{p}=0.008)$. However, the sim-

Table 3. - Logistic regressions of inhalant allergenspecific immunoglobulin E on Toxocara seroprevalence, environment, district, sex, age and school: Dutch elementary schoolchildren 1989-1992

\begin{tabular}{|c|c|c|c|c|c|}
\hline \multirow[t]{2}{*}{ Variable } & \multicolumn{2}{|c|}{ Cases } & \multirow{2}{*}{$\begin{array}{c}\text { Crude } \\
\text { OR }\end{array}$} & \multirow{2}{*}{$\begin{array}{c}\text { Adjusted } \\
\text { OR }\end{array}$} & \multirow[t]{2}{*}{$95 \% \mathrm{CI}^{\$}$} \\
\hline & Total* & $(\%)$ & & & \\
\hline \multicolumn{6}{|l|}{ Toxocara } \\
\hline Negative & $193 / 1238$ & (16) & BL & $\mathrm{BL}$ & \\
\hline Positive & $28 / 112$ & (25) & 1.81 & 1.66 & $1.04-2.65$ \\
\hline \multicolumn{6}{|c|}{ Environment } \\
\hline Urban & $126 / 647$ & (20) & BL & $\mathrm{BL}$ & \\
\hline Rural & $95 / 703$ & (14) & 0.65 & 0.61 & $0.43-0.87$ \\
\hline \multicolumn{6}{|l|}{ District } \\
\hline Utrecht & $97 / 647$ & (15) & BL & BL & $0.86-1.74$ \\
\hline Eindhoven & $124 / 684$ & (18) & 1.30 & 1.23 & \\
\hline \multicolumn{6}{|c|}{ Sex } \\
\hline Boys & $133 / 671$ & (20) & BL & BL & \\
\hline Girls & $88 / 679$ & (13) & 0.60 & 0.61 & $0.45-0.82$ \\
\hline \multicolumn{6}{|l|}{ Age (yrs) } \\
\hline \multicolumn{3}{|c|}{ School (random) } & & \multicolumn{2}{|c|}{$\mathrm{p}$-value $=0.186$} \\
\hline
\end{tabular}

*: number of children with inhalant allergen-specific immunoglobulin E versus the total number of children in that category; : odds ratio (OR) adjusted for all other variables in the table; $\$$ : $95 \%$ confidence intervals (CI) of the adjusted ORs; BL: baseline.

plest ANCOVA model that adequately described the relationships between eosinophil number and Toxocara, district, environment, sex, school and age included, in addition to the main effects of all factors, a significant second order interaction between Toxocara seroprevalence, district and environment $(\mathrm{p}=0.043)$. We have interpreted this as the effect of Toxocara seroprevalence on eosinophil numbers being different in each of the four subgroups formed by combining the levels of district and environment. Results for these groups are presented in table 4. Although the direction of the difference between Toxocara-seronegative and seropositive groups was the same in all groups, the magnitudes of the differences varied considerably. The largest and only significant difference was found in the rural vicinity of

Table 4. - Analysis of covariance of eosinophil numbers in relation to Toxocara seroprevalence, district, environment, sex, age and school: Dutch elementary schoolchildren 1989-1992

\begin{tabular}{|c|c|c|c|c|}
\hline & & Eosinophils & cells $\cdot \mu \mathrm{L}^{-1}$ & p-value \\
\hline & $\mathrm{n}$ & L-S Mean ${ }^{\dagger}$ & $95 \% \mathrm{CI}^{\dagger}$ & \\
\hline Utrecht: urban & & & & \\
\hline Toxocara -ve & 303 & 198 & 180-219 & \\
\hline$+\mathrm{ve}$ & 24 & 260 & $183-367$ & 0.1404 \\
\hline Utrecht: rural & & & & \\
\hline Toxocara -ve & 304 & 178 & 161-197 & \\
\hline$+\mathrm{ve}$ & 26 & 195 & $141-269$ & 0.6050 \\
\hline Eindhoven: urbar & & & & \\
\hline Toxocara -ve & 287 & 190 & $172-210$ & \\
\hline$+\mathrm{ve}$ & 38 & 195 & $148-255$ & $0.8767^{\ddagger}$ \\
\hline Eindhoven: rural & & & & \\
\hline Toxocara -ve & 340 & 141 & $129-154$ & \\
\hline$+v e$ & 24 & 241 & $171-339$ & $0.0030^{\ddagger}$ \\
\hline Sex & & & & \\
\hline Boys & 672 & 205 & $187-226$ & \\
\hline Girls & 674 & 189 & $171-208$ & $0.0669^{\S}$ \\
\hline Age (yrs) & & $.0179 ; 0.0094$ & & 0.0576 \\
\hline School & & & & 0.3259 \\
\hline $\begin{array}{l}\text { n: number of ch } \\
\text { positive. }{ }^{\dagger} \text { least } \\
\text { dence intervals ( } \\
\ddagger \text { p-value belong } \\
\text { cara-negative and } \\
\text { binations of the lo } \\
\S \text { : p-value of the } \\
\text { the sexes; } \# \text { coef } \\
\text { age indicating th } \\
\text { change of } 1 \text { yr in }\end{array}$ & $\begin{array}{l}\text { els of } \\
\text { differ }\end{array}$ & $\begin{array}{l}\mathrm{n} \text { that categor } \\
\text { (L-S) means } \\
\text { nsformed bacl } \\
\text { le tests of the } \\
\text { e groups withi } \\
\text { the factors, di } \\
\text { nce in eosino } \\
\text { and standard } \\
\text { ge in log eos }\end{array}$ & $\begin{array}{l}\mathrm{k} \text { to the or } \\
\text { contrast be } \\
\mathrm{n} \text { each of } \mathrm{tl} \\
\text { strict and e } \\
\text { phil numb } \\
\text { error of th } \\
\text { sinophil nu }\end{array}$ & $\begin{array}{l}\text { ive; +ve: } \\
\% \text { confi- } \\
\text { hal scale; } \\
\text { en Toxo- } \\
\text { our com- } \\
\text { ronment; } \\
\text { between } \\
\text { ovariable } \\
\text { ers by a }\end{array}$ \\
\hline
\end{tabular}


Eindhoven, whilst in Eindhoven city a very small difference was found. The two samples from Utrecht were intermediate. There was a considerable variation among the seropositive groups, and less so among the seronegative ones.

The number of eosinophils was higher in boys than in girls, a difference that was borderline significant (table 4). Furthermore, a small and almost significant negative trend with age was found, corresponding with a decrease of almost $2 \%$ in the number of eosinophils for a $1 \mathrm{yr}$ increase in age. No significant differences between schools were found. Least squares means transformed back to the original scale ranged 166-247 cells. $\mu \mathrm{L}^{-1}$ (detailed results not shown).

For the IgE values, the same model was found to be adequate as that used for the eosinophil numbers. Therefore, for this variable also, a second order interaction between district, environment and Toxocara $(p=0.0402)$ was included in the model. Overall, a significantly higher serum total $\mathrm{IgE}$ concentration was found in the seropositive group (126.9 IU $\cdot \mathrm{mL}^{-1}$; 95\% CI 94-172 IU.mL-1) than in the seronegative group $\left(66.3 \mathrm{IU} \cdot \mathrm{mL}^{-1} ; 95 \% \mathrm{CI}\right.$ $\left.61-73 \mathrm{IU} \cdot \mathrm{mL}^{-1} ; \mathrm{p}=0.0001\right)$. In this case, also, examination of this difference in the four subpopulations separately revealed a substantial variation (table 5). Large and statistically significant differences were found in the city of Utrecht and in rural Eindhoven. A much smaller difference was observed in the city of Eindhoven, and a very small difference in rural vicinity of Utrecht. Again, the direction of the difference was the same in all subgroups. Serum IgE levels were higher in children

Table 5. - Analysis of covariance of serum total immunoglobulin E (lgE) levels in relation to Toxocara seroprevalence, district, environment, sex, age and school: Dutch elementary schoolchildren 1989-1992

\begin{tabular}{|c|c|c|c|c|c|}
\hline & \multirow[b]{2}{*}{$\mathrm{n}$} & \multicolumn{2}{|c|}{ Serum total $\mathrm{IgE} \mathrm{IU} \cdot \mathrm{mL}^{-1}$} & \multirow[b]{2}{*}{ p-value } \\
\hline & & & L-S Mean ${ }^{\dagger}$ & $95 \% \mathrm{CI}^{\dagger}$ & \\
\hline \multicolumn{6}{|c|}{ Utrecht:urban } \\
\hline \multirow{2}{*}{ Toxocara } & $-v e$ & 306 & 85.1 & $70.7-102.5$ & \\
\hline & +ve & 24 & 212.4 & $110.6-407.8$ & 0.0078 \\
\hline \multicolumn{6}{|c|}{ Utrecht:rural } \\
\hline \multirow{2}{*}{ Toxocara } & -ve & 315 & 45.7 & $38.1-54.9$ & \\
\hline & $+\mathrm{ve}$ & 27 & 54.6 & $29.8-100.0$ & 0.5824 \\
\hline \multicolumn{6}{|c|}{ Eindhoven:urban } \\
\hline \multirow[t]{3}{*}{ Toxocara } & -ve & 286 & 76.0 & 63.0-91.7 & \\
\hline & +ve & 38 & 120.2 & $72.1-200.2$ & 0.0998 \\
\hline & \multicolumn{5}{|c|}{ Eindhoven:rural } \\
\hline \multirow[t]{2}{*}{ Toxocara } & -ve & 340 & 65.4 & $55.2-77.6$ & \\
\hline & $+\mathrm{ve}$ & 24 & 186.0 & $97.8-353.6$ & $0.0021^{*}$ \\
\hline \multicolumn{6}{|l|}{ Sex } \\
\hline Boys & & 678 & 101.2 & $84.9-120.6$ & \\
\hline Girls & & 674 & 83.2 & 69.1-100.0 & $0.0249 \S$ \\
\hline Age (yrs) & & \multirow{2}{*}{\multicolumn{3}{|c|}{$(0.0844 ; 0.0176)^{\#}$}} & 0.0001 \\
\hline School & & & & & 0.0001 \\
\hline
\end{tabular}

$\mathrm{n}$ : number of children in that category; -ve: negative; +ve: positive. $\dagger$ : least squares (L-S) means and their $95 \%$ confidence intervals $(\mathrm{CI})$, transformed back to the original scale; $\ddagger$ : p-value belonging to the tests of the contrast between Toxocara-negative and positive groups within each of the four combinations of the levels of the factors, district and environment; \$: p-value of the difference in $\operatorname{IgE}$ concentrations between the sexes; \#: coefficient and standard error of the covariable age indicating the change in $\ln \operatorname{IgE}$ level by a change of $1 \mathrm{yr}$ in age.
Table 6. - Serum total immunoglobulin E (IgE) concentration versus Toxocara-specific IgE in Toxocaraseropositive and seronegative samples

\begin{tabular}{lcr}
\hline No. & $\begin{array}{c}\text { Total IgE } \\
\mathrm{kU} \cdot \mathrm{L}^{-1}\end{array}$ & $\begin{array}{c}\text { Tox.-specific IgE } \\
\mathrm{U} \cdot \mathrm{L}^{-1}\end{array}$ \\
\hline \multicolumn{2}{c}{ Toxocara seropositive } & \\
1 & 727 & 40.0 \\
2 & $>2000$ & 2.5 \\
3 & $>2000$ & $<1.0$ \\
4 & 673 & 1000.0 \\
5 & 481 & $<1.0$ \\
6 & 866 & 3.0 \\
Toxocara seronegative & \\
7 & 1261 & 4.0 \\
8 & 1669 & $<1.0$ \\
9 & $>2000$ & $<1.0$ \\
10 & 1243 & $<1.0$ \\
11 & 1759 & $<1.0$ \\
12 & $>2000$ & $<1.0$ \\
\hline
\end{tabular}

$\dagger$ : serum total $\operatorname{IgE}$ concentration expressed in international kilo units per litre of serum; $\$$ : Toxocara-specific IgE expressed in Toxocara units per litre of serum; Tox.: Toxocara.

from an urban $\left(113.4 \mathrm{IU} \cdot \mathrm{mL}^{-1}\right)$ than from a rural environment (74.2 IU $\left.\cdot \mathrm{mL}^{-1}, \mathrm{p}=0.0055\right)$, higher in males than in females, and increased almost $9 \%$ with a 1 yr increase in age (table 5). IgE levels varied widely among schools, ranging 29.4-237.8 IU. $\mathrm{mL}^{-1}$, a variation that was highly significant.

\section{Toxocara-specific IgE}

Serum samples, selected from the Toxocara-seropositive and seronegative groups on the basis of total serum IgE concentrations, were analysed for Toxocara-specific IgE. No relationship was found between levels of total $\operatorname{IgE}$ and Toxocara-specific IgE concentrations in the six seropositive samples, two of which even demonstrated absence of specific IgE. Five of the six seronegative samples were negative for specific IgE. One sample, however, demonstrated a low positive reaction (table 6).

\section{Risk factors}

Relationships between Toxocara seroprevalence and the putative risk factors were adjusted for confounding effects of district, environment, school, sex and age. Having kept a dog as a pet at sometime in the life of a child resulted in higher odds for having Toxocara antibodies (OR 1.52; 95\% CI 1.01-2.29). Currently keeping a dog, raised the odds for having Toxocara antibodies only slightly, and not significantly (OR 1.22; 95\% CI 0.801.86). Similarly, having a dog in the past but not at present raised the odds, but not significantly (OR 1.47; 95\% CI 0.98-2.22). Having kept a cat at sometime, or having a cat in the past but not at present, also yielded (not significantly) higher odds (OR 1.23; 95\% CI 0.80-1.86 and OR 1.49; 95\% CI 0.95-2.33, respectively). Currently having a cat was not related to Toxocara seroprevalence at all (OR 0.99; 95\% CI 0.59-1.67). The dog 
ownership variables were included in the models describing the associations between Toxocara seroprevalence and allergic manifestations to check for possible confounding effects. This did not appreciably lower the odds ratios for Toxocara, and thus did not change the findings.

Use of public playgrounds and the amount of contact with animals outside the home were measured on a three-point scale, having the categories: no, infrequent, and frequent use or contact. Of the children reporting no contact with animals outside the home, $14.5 \%$ were Toxocara seropositive. In the groups reporting infrequent and frequent contact these percentages were 6 and $10.5 \%$, respectively. Frequent and infrequent contact, therefore, resulted in lower odds for Toxocara seroprevalence when compared to the group that reported no contact. The OR for infrequent contact was $0.42(95 \%$ CI 0.24-0.74), which was significant, and for frequent contact 0.77 (95\% CI 0.42-1.41), which was not significant.

Of the children who never played in public playgrounds, $9.3 \%$ were Toxocara seropositive; $6.9 \%$ were seropositive in the group who played only infrequently in these playgrounds; and $10.4 \%$ in those who did so frequently. Thus, when using the group who never played in public playgrounds as the baseline category, the OR for infrequent use was 0.73 (95\% CI 0.42-1.29) and for frequent use 1.11 (95\% CI 0.62-2.00), neither of them being significant.

\section{Discussion}

The main aim of the present study was to investigate whether or not an association exists between allergyrelated phenomena and Toxocara seroprevalence. Such an association was hypothesized on the basis of characteristics that toxocarosis and allergy have in common, i.e. excessive $\operatorname{IgE}$ production, eosinophilia, and respiratory complaints $[1,3,13]$. Excessive $\operatorname{IgE}$ production after contact with IgE-stimulating agents is an inherited phenomenon [21]. Young children with an atopic condition risk development of allergic asthma during growth [22]. Since accumulated exposure to inhaled allergens of 4-12 yr old children may not yet have initiated allergic manifestations, this association could be best studied in this age group.

We found that asthma/recurrent bronchitis and allergic reaction on animal contact were diagnosed significantly more often in the Toxocara-seropositive group than in the seronegative group. Moreover, inhaled allergen-specific IgE was observed significantly more often among Toxocara-seropositive than among seronegative individuals. Furthermore, overall eosinophil numbers and total IgE levels were significantly increased in the seropositive group as compared to the seronegative group. However, an analysis of the four subsamples revealed that, although the direction of the differences was the same in all four subgroups, a significant increase in eosinophil numbers existed in rural Eindhoven, and significantly raised serum total $\mathrm{IgE}$ concentrations in urban Utrecht and rural Eindhoven.

The observed associations between Toxocara seroprevalence and allergy-related variables, including aller- gen-specific IgE, strongly suggest that Toxocara stimulates the production of allergen-specific IgE. Since various parasitic infections induce polyclonal $\mathrm{B}_{\varepsilon}$-cell activation $[14,15]$, it is conceivable that infection with $\operatorname{IgE}-$ inducing parasites, including Toxocara, results in nonspecific stimulation of dormant allergic manifestations in children prone to atopy. The causative mechanism may be that both conditions stimulate the immune response in a similar fashion. Allergens and parasite-derived antigens stimulate type 0 T-helper cells to develop into type 2 T-helper cells (Th2), which produce the cytokines interleukin (IL)-4 and IL-5 [23, 24]. IL-4 stimulates IgE production by inducing the B-cell switch from $\mu \delta$ to $\varepsilon$ expression [24]. IL-5 stimulates eosinophil proliferation and maturation [23]. Under normal conditions, type 1 T-helper cells (Th1), which produce interferon-gamma $($ IFN- $\gamma$ ), are also activated. IFN- $\gamma$ is responsible for the downregulation of Th2 cell activity [25]. The balance between the two T-helper cell subpopulations in allergy susceptible individuals may be disturbed in such a way that no downregulation of the Th2 cells occurs.

The ability of Toxocara larvae to survive in their hosts for many months may stimulate Th2 cells and, consequently, IgE production for a longer period. We demonstrated in Toxocara-infected mice that elevated serum total IgE levels lasted for at least 3 months postinfection [8]. Recently, vAN OMMEN et al. [26] demonstrated in a trinitrophenol (TNP)-keyhole limpet haemocyanin (KLH) immunization model, that longstanding elevated IgE levels induced a decrease in antigen-specific $\operatorname{IgE}$, but an increase in serum total $\operatorname{IgE}$. It was demonstrated that parasites, such as Toxocara, induced high serum total IgE levels, of which only a fraction was parasite-specific $[14,15]$. Thus, it may be the case that allergenprimed resting $\mathrm{B}_{\varepsilon}$-cells, induced previously to Toxocara infection, and newly Toxocara-primed $\mathrm{B}_{\varepsilon}$-cells are stimulated, simultaneously, to produce allergen-specific IgE and Toxocara-specific IgE, respectively. This supposition was supported by the results of Toxocara-specific IgE estimated in a few selected serum samples from infected and noninfected children participating in the present study.

No relationship was found between the level of total IgE concentration and that of Toxocara-specific IgE in the seropositive samples. Magnaval [27] reported similar observations from patients with toxocarosis in France. We performed a study among children selected on the basis that they (and their relatives) did not have or had not had established allergic asthma. Both groups demonstrated increased IgE levels in the Toxocaraseropositive groups. IgE levels, although increased as compared to the seronegative children, remained within normal limits in the asthma-free group, whereas in the asthma group the already highly increased IgE level in seronegative children was doubled in the seropositive children [28]. It is plausible that Toxocara infection initially induces an IgE increase in a majority of infected individuals, and that only those with unbalanced T-helper cell function demonstrate excessive IgE production.

Our results are in agreement with the observations of HAGEL et al. [29] from a study performed in Venezuela. They observed that rural children with low socioeconomic background had a high and diverse parasite burden, 
and that urban children from medium to high socioeconomic backgrounds had a low and less diverse parasite burden. Both had highly increased serum total IgE levels, but the rural children presented significantly less often with positive skin tests on allergen challenge than urban children. They proposed that, in the case of high parasite burden, mast cell receptors were saturated with $\mathrm{IgE}$ molecules of great diversity. This prevented the bridging of two identical $\mathrm{IgE}$ molecules upon allergen challenge and the subsequent histamine release. In the case of low and less diverse parasite burden, the $\operatorname{IgE}$ molecules on mast cell receptors would be more homogeneous, allowing the bridging of $\mathrm{IgE}$ molecules upon allergen challenge followed by histamine release. Differences between socioeconomic classes in the Netherlands are much smaller than in Venezuela, and all classes are probably comparable to Venezuela's highest socioeconomic class. Children harbouring different helminthic parasites have become rare in the Netherlands [28].

A relationship between eosinophil numbers and Toxocara seroprevalence was demonstrated in the sample, although the increase was only significant in the subpopulation of rural Eindhoven. Eosinophils are tissue cells and migrate to inflammatory sites. In a mouse study, we found that infection caused a rapid increase in blood eosinophils, returning to near normal values after 4 weeks. Eosinophils were still present at inflammatory sites in the tissues (lungs) 3 months after infection [8]. TAYLOR et al. [7] investigated Toxocara seroprevalence among children reporting with allergic complaints at an out-patient department. Although blood eosinophilia was observed, it was not a consistent characteristic. It is plausible that, during the acute phase, eosinophils migrate from bone marrow to inflamed tissues via the peripheral circulation. When the inflammation has become chronic, the chemotactic stimulus and, thus, the stimulus for eosinophil migration decreases.

In addition to the association between allergy-related phenomena and Toxocara infection, we studied differences in Toxocara seroprevalence among schools, between girls and boys, between urban and rural environments, and between the districts of Utrecht and Eindhoven, and we tried to identify risk factors for Toxocara infection.

In the sample as a whole, significantly more boys than girls had Toxocara antibodies. This difference varied in the four subpopulations, and was even reversed in the city of Eindhoven, though not significantly so. There were no differences between the districts of Utrecht and Eindhoven, nor between urban and rural environments. However, we did find a very large variation among the schools, which is hard to explain. Variations in seropositivity within countries have been reported by other investigators [30-32]. This observation was attributed mainly to factors such as social class [33] and contact with animals. In the present study, no relationship was found between seroprevalence and socioeconomic class, which was investigated in the cities only (results not shown). Rural schools are attended by children irrespective of socioeconomic background, living both in villages and on farms in the neighbourhood. Analysis of apparent risk factors for Toxocara infection yielded no clear relationships. Similar results (including the variability among schools) were obtained in a previous study carried out at 15 schools in two Dutch cities [9]. Although contamination of the outside environment by pets is the main source of infection, environment-related risks analysed in a cross-sectional study did not clarify how children became infected, nor did it explain the large variation among schools. A longitudinal study and investigation into factors such as children's behaviour when playing, and hygiene of the inside environment at home and at school may provide a better understanding of infection dynamics and merit investigation.

Our study showed that children from urban areas more often than those from rural areas had allergen-specific IgE. One explanation may be that the quality both of indoor and outdoor environment in cities is different from that in rural areas, in such a way that the immune response in susceptible individuals is triggered to produce $\operatorname{IgE}$ at a younger age.

In conclusion, an association was demonstrated between Toxocara seroprevalence and various manifestations of allergic disease, including allergic asthma. It was suggested that the mechanisms by which Toxocara stimulates these manifestations were based on a combination of a hereditary tendency for skewing to type 2 T-helper cell function and the longevity of the parasite within in its host. Longstanding elevated levels of interleukin-4 may have induced excessive production of polyclonal immunoglobulin $\mathrm{E}$ which was directed partly against inhaled allergens. As excessive immunoglobulin E production, which has been shown to be hereditary [21], appears to play a role, we speculate that only children with an atopic predisposition demonstrate an association between Toxocara infection and allergic manifestations.

\section{References}

1. Ninan TK, Russell G. Respiratory symptoms and atopy in Aberdeen schoolchildren: evidence from two surveys 25 years apart. BMJ 1992; 305: 1395-1399.

2. Robertson CF, Heycock W, Bishop J, Nolan T, Olinsky A, Phelan PD. Prevalence of asthma in Melbourne children: changes over 26 years. BMJ 1991; 302: 1116-1118.

3. Sears MR, Burrows B, Flannery EM, Herbison GP, Hewitt CJ, Holdaway MD. Relation between airway responsiveness and serum $\operatorname{IgE}$ in children with asthma and in apparently normal children. $N$ Engl J Med 1991; 325: 1067-1071.

4. Kjellman NIM, Croner S. Cord blood IgE determination for allergy prediction: a follow-up to seven years of age in 1,651 schoolchildren. Ann Allergy 1984; 53: 263-268.

5. Platts-Mills TAE, Ward GW Jr, Sporik R, Gelber LE, Chapman MD, Heymann PW. Epidemiology of the relationship between exposure to indoor allergens and asthma. Int Arch Allergy Appl Immunol 1991; 94: 339-345.

6. Arshad SH, Matthews S, Gant C, Hide DW. Effect of allergen avoidance on development of allergic disorders in infancy. Lancet 1992; 339: 1493-1497.

7. Taylor MRH, O'Connor P, Keane CT, Mulvihill E, Holland C. The expanded spectrum of toxocaral disease. Lancet 1988; 26: 692-695.

8. Buijs J, Lokhorst WH, Robinson J, Nijkamp FP. Toxocara canis-induced murine pulmonary inflammation: analysis of cells and proteins in lung tissue and bronchoalveolar lavage fluid. Parasite Immunol 1994; 16: 1-9. 
9. Buijs J, Borsboom G, Van Gemund JJ, et al. Toxocara seroprevalence in 5 year old elementary schoolchildren: relation with allergic asthma. Am J Epidemiol 1994; 140: 839-847.

10. Schantz PM, Meyer D, Glickman LT. Clinical, serologic and epidemiologic characteristics of ocular toxocariasis. Am J Trop Med Hyg 1079; 28: 24-28.

11. Bowman DD, Kika-Grieve M, Grieve RB. Circulating excretory-secretory antigen levels and specific IgG and IgM responses in mice infected with Toxocara canis. Am J Trop Med Hyg 1987; 36: 75-82.

12. Buijs J, Egbers WEC, Lokhorst WH, Savelkoul HFJ, Nijkamp FP. Toxocara-induced eosinophilic inflammation: airway function and effect of anti-IL-5. Am J Respir Crit Care Med 1995; 151: 873-878.

13. Desowitz ES, Rudoy R, Barnwell JW. Antibodies to canine helminth parasites in asthmatic and nonasthmatic children. Int Arch Allergy Appl Immunol 1981; 65 361-366.

14. Jarrett E, Mackenzie S. Parasite-induced "nonspecific" IgE does not protect against allergic reactions. Nature 1980; 283: 302-304.

15. Turner LK, Feddema L, Quinn EH. Nonspecific potentiation of immunoglobulin $\mathrm{E}$ by parasitic infections in man. Int Arch Allergy Appl Immunol 1979; 58: 232-236.

16. van Knapen F, van Leusden J, Conijn van Spaendonk MAE. Human toxocarosis: diagnosis and incidence in the Netherlands. Tijdschr Diergeneeskd 1983; 108: 469474.

17. Van Knapen F, Van Leusden J, Polderman AM, Franchimont JH. Visceral larva migrans: examinations by means of enzyme-linked immunosorbent assay of human sera for antibodies to excretory-secretory antigens of the secondstage larvae of Toxocara canis. Z Parasitenkd 1983; 69: 113-118.

18. Magnaval J-F, Fabre R, Maurières P, Charlet J-P, De Larrard B. Evaluation of an immunoenzymatic assay detecting specific anti-Toxocara immunoglobulin $\mathrm{E}$ for diagnosis and post-treatment follow-up of human toxocariasis. J Clin Microbiol 1992; 30: 2269-2274.

19. Statistics and Epidemiology Research Corporation. EGRET statistical software. Seattle, SERC Inc., 1988.

20. SAS Institute Inc. SAS/STAT user's Guide. Version 6. 4th Edn. Volume 2. Cary, NC, SAS Institute Inc., 1989.

21. Cookson WOCM, Hopkin JM. Dominant inheritance of atopic immunoglobulin E responsiveness. Lancet 1988; i: $86-87$.

22. Chandra RK, Puri S, Cheema PJ. Predictive value of cord blood IgE in the development of atopic disease and role of breast-feeding in its prevention. Clin. Allergy 1984; 15: 517-522.

23. Mosmann TR, Coffman RL. Two types of mouse helper T-cell clones: implications for immune regulation. Immunol Today 1987; 8: 223-227.

24. Coffman RL, Lebman DA, Rothman P. Mechanism and regulation of immunoglobulin isotype switching. $A d v$ Immunol 1993; 54: 229-270.

25. Coffman RL, Carty J. A T-cell activity that enhances polyclonal IgE production and its inhibition by interferon- $\gamma$. J Immunol 1986; 136: 949-954.

26. Van Ommen R, Vredendaal AECM, Savelkoul HFJ. Prolonged in vivo IL-4 treatment inhibits antigen-specific IgG1 and IgE formation. Scand J Immunol 1994; 40: 1-9.

27. Magnaval JF. Eléments nouveaux dans la séméiologie des "larva migrans" viscérales. Presse Méd 1987; 16: 151-154.

28. Buijs J. Toxocara seroprevalence in asthmatic and nonasthmatic children: relation with total $\mathrm{IgE}$ and allergenspecific IgE. Thesis: Toxocara infection and airway function: an experimental and epidemiological study. 1993; Chapter 9, 159-175. ISBN 90-393-0315-0.

29. Hagel I, Lynch NR, DiPrisco MC, Lopez RI, Garcia NM. Allergic reactivity of children of different socioeconomic levels in tropical populations. Int Arch Allergy Immunol 1993; 101: 209-214.

30. Worley G, Green JA, Frottingham TE, et al. Toxocara canis infection: clinical and epidemiological associations with seropositivity in kindergarten children. $J$ Infect Dis 1984; 149: 591-597.

31. Ree GH, Voller A, Rowland HA. Toxocariasis in the British Isles, 1982-1983. Br Med J 1981; 288: 628-629.

32. Marmor M, Glickman LT, Shofer F, et al. Toxocara canis infection in children: epidemiologic and neuropsychologic findings. Am J Public Health 1987; 77 : 554-559.

33. Embil JA, Tanner CE, Pereira LH, Staudt M, Morrison EG, Gualiazzi, DA. Seroepidemiologic survey of Toxocara canis infection in urban and rural children. Public Health 1988; 102: 129-133. 